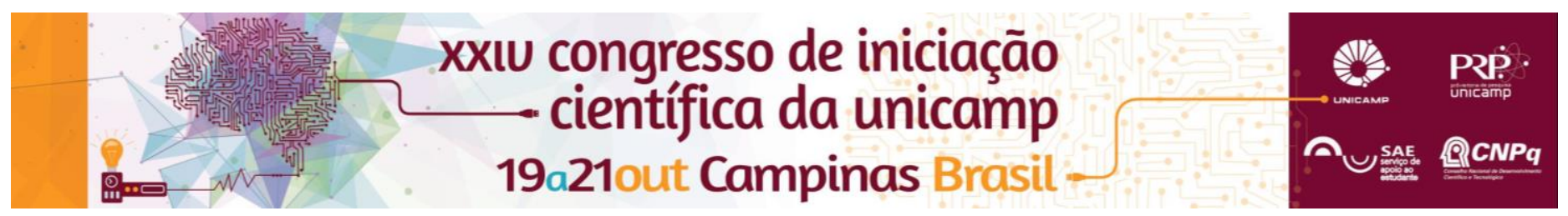

\title{
USO DE VEÍCULOS AÉREOS NÃO TRIPULADOS (VANTS) COMERCIAiS PARA A DETECÇÂO DOS PROBLEMAS DE PLANTABILIDADE EM MILHO.
}

\author{
Gisela M. Silva*, Angel P. Garcia, Isabela O. P. S. Simões, Lucas S. Peixoto, Rodrigo L. de Paulo
}

\begin{abstract}
Resumo
Com o grande aumento da área voltada para a produção agrícola no Brasil, houve a necessidade do uso da mecanização para os processos de preparo do solo, semeadura e colheita, gerando uma preocupação com a qualidade das operações, em especial a semeadura. Atualmente, o processo de determinação da distância entre plantas de uma mesma linha de semeadura é manual e propenso a falhas. Quantificar essas falhas em porcentagem através da classificação de imagens coletadas por VANTs comerciais, pelo método de Mínima Distancia, é uma alternativa para a detecção de problemas de plantabilidade que podem ser utilizados como alternativa no monitoramento agrícola para gerar argumentos para tomadas de decisão com relação à cultura.
\end{abstract}

\section{Palavras-chave:}

Processamento de imagens, Mínima distância, Classificadores.

\section{Introdução}

O Acompanhamento do crescimento e desenvolvimento de uma cultura é imprescindível para a tomada de decisões com relação a adubação, irrigação, drenagem, necessidade de replantio, entre outros. Essas decisões podem ser tomadas analisando falhas de semeadura, e essas falhas podem ser analisadas com imagens de obtidas com Veículos aéreos não tripulados (VANTs), pois essas falhas nos padrões de espaçamentos são claramente detectadas com essas imagens (JORGE et al., 2004). Segundo Stolf (1986) falha é a projeção da distância entre duas plantas consecutivas.

A população de plantas é o fator que menos afeta a produtividade, desde que as plantas estejam distribuídas uniformemente na área (ENDRES, 1996).

$O$ objetivo deste trabalho foi verificar a eficiência do uso de Veículos Aéreos Não Tripulados (VANT) comerciais para a detecção de problemas de plantabilidade. $O$ trabalho consistiu na avaliação do processamento das imagens coletadas com o VANT, que foram analisadas com os softwares ENVI 5.1, ArcMap 10.3 e MatLab.

\section{Resultados e Discussão}

Foram classificadas pelos três classificadores (Máxima verossimilhança, Mínima distância e distância de Mahalanobis) as imagens de 20, 40 e 60 metros de altura. Para o processo de validação foi através da acurácia da classificação (Exatidão global e Índice de Kappa) e as porcentagens de palha, solo e milho, para as três alturas de análise e para os três classificadores utilizados.

O processamento das imagens foi feito através de softwares de Processamento Digital de Imagens, Envi 5.1 e ArcGis 10.3 e também do software matemático MatLab, onde foram testados diversos classificadores e filtros a fim de identificar o mais adequado.

As porcentagens das classes temáticas mostram que a maior variação ocorre na classe de palha, onde os três classificadores apresentaram resultados totalmente diferentes, mostrando que para essa altura de 40 metros a classe palha foi a que apresentou maior confusão entre os classificadores, seguidas pelo solo; 0 milho teve percentual muito semelhante entre os classificadores.

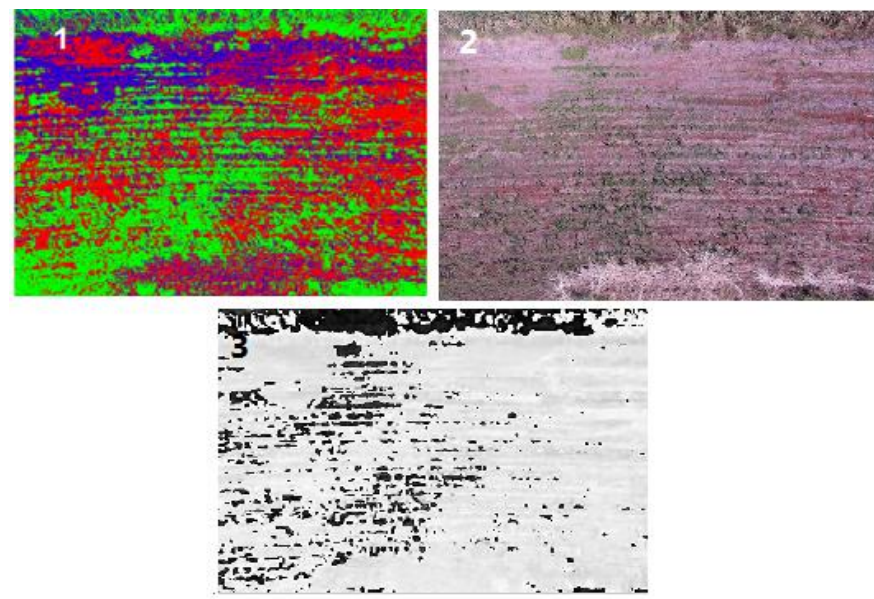

Figura 1. Imagens classificadas, para a altura de 40 metros, pelos métodos da mínima distância, com a representação de três classes temáticas, Palha, Solo e Milho. (Imagem 1), Imagem sem processamento (Imagem 2) Imagem processada no MatLab (Imagem 3).

\section{Conclusões}

Dentro os estádios vegetativos do milho, podemos concluir que o estádio V3 não conseguimos analisar cada indivíduo.

Para imagens em RGB o classificador melhor avaliado foi o da Mínima Distancia, que apresentou melhor acurácia para ambas as três alturas de análise e apresentou menores variações entre as porcentagens de milho.

\section{Agradecimentos}

Agradecimento a todos membros do LIC, do laboratório de geoprocessamento e da GeoCrop.

${ }^{1}$ ENDRES, V. C. Espaçamento, densidade e época de semeadura. In: EMBRAPA. Centro de Pesquisa Agropecuária do Oeste (Dourados, MS). Soja: recomendações técnicas para Mato Grosso do Sul e Mato Grosso. Dourados, 1996.p. 82-85. (Circular Técnica, 3).

${ }^{2}$ JORGE, L.A.C.; TRINDADE JUNIOR, O.; DAINESE, R.C.; CEREDA JUNIOR, A. Aeromodelo para sensoriamento remoto em agricultura de precisão. In: Gis Brasil. Anais... São Paulo, 2004.

${ }^{3}$ STOLF, R. Metodologia de avaliação de falhas nas linhas de cana de açúcar. STAB, Piracicaba, v.4, n.6, p.22, jul./ago.1986. 